\title{
Drosophila Serotonin Transporters Have Voltage-Dependent Uptake Coupled to a Serotonin-Gated Ion Channel
}

\author{
A. Galli, C.I. Petersen, M. deBlaquiere, R.D. Blakely, and L.J. DeFelice \\ Center for Molecular Neuroscience, Department of Pharmacology, Vanderbilt University Medical Center, Nashville, \\ Tennessee 37232-6600
}

\begin{abstract}
Serotonin (5HT) transporters (SERTs) couple to existing ion gradients to transport $5 \mathrm{HT}$ into presynaptic terminals. In mammalian SERTs, the transport cycle is reported as electroneutral, with a translocation of zero net charge, and $5 \mathrm{HT}$ uptake is independent of membrane voltage. Yet mammalian SERTs exhibit 5HT-induced currents, and Drosophila SERTs (dSERTs) show voltage-dependent uptake. Thus, the relationship between uptake and current remains controversial; furthermore, the number of $5 \mathrm{HT}$ molecules translocated per ion channel event is unknown. To investigate this, we have used heterologous expression of cloned dSERTs to measure 5HT flux and dSERT currents concurrently under voltage clamp, and we have used fluctuation analysis to measure the size of the elementary ionic events in the same cells. RNA-injected Xenopus oocytes accumulate $5 \mathrm{HT}$, and paroxetine or desipramine inhibit this uptake. RNA-injected oocytes also display paroxetine-
\end{abstract}

sensitive $5 \mathrm{HT}$-induced currents and $5 \mathrm{HT}$-independent leak currents. Na replacement decreases the uptake and the induced currents. $5 \mathrm{HT}$-induced current and $5 \mathrm{HT}$ uptake both increase at negative potentials, where $5 \mathrm{HT}$ carries $\sim 5 \%$ of the induced current. Recently, several groups have reported similar phenomena for other transporters, in which transmitter-induced currents exceed the predictions of coupled transport. We now provide evidence that in dSERT, $\sim 5005 \mathrm{HT}$ molecules are translocated per channel opening, which, at $-20 \mathrm{mV}$, carries $\sim 10,000$ electronic charges. These data support a model in which 500 SERT cycles occur for each $5 \mathrm{HT}$-induced channel opening or a model in which $5005 \mathrm{HT}$ molecules and 10,000 electronic charges pass through a common pore.

Key words: serotonin; transporter; uptake; antidepressants; channels; Xenopus oocytes
Neurotransmitter transporters couple the gradients of ions to the flux of the transmitter (Amara and Kuhar, 1993; Lester et al., 1994). Na- and Cl-coupled transporters constitute a large family of related proteins that take up GABA, catecholamines, and serotonin (5HT). Na-coupled transporters make up a separate gene family for the uptake of glutamate and aspartate. Recently, several groups have described transporter-associated currents that exceed the predictions of stoichiometric transport (DeFelice and Blakely, 1996; Sonders and Amara, 1996). Excess currents have been observed in heterologous expression systems for 5HT (Corey et al., 1994; Mager et al., 1994), glutamate (Vandenberg et al., 1995; Wadiche et al., 1995a,b), norepinephrine (Galli et al., 1995, 1996), GABA (Cammack et al., 1994, 1996), and dopamine (Sonders et al., 1997) transporters. Similar phenomena appear in native preparations for 5HT (Bruns et al., 1993), GABA (Cammack and Schwartz, 1993), and glutamate (Larson et al., 1996) transporters. Here we report the first data to correlate in the same cells the movement of transmitter with the channel activity underlying the transmitter-induced current. We propose two models that relate this information to voltage-dependent uptake.

Received Dec. 3, 1996; revised Jan. 31, 1997; accepted Feb. 22, 1997.

This work was supported by National Institutes of Health Grants NS-34075, NS-33373, and DA-07390, and National Alliance for Research on Schizophrenia and Depression Established Investigator Awards to L.J.D. and R.D.B. We thank Scott Ramsey for his assistance in setting up the initial experiments for dSERT cRNAinjected oocytes and Dawn Borromeo for technical assistance. The dSERT clone was a generous gift of Dr. H. Niznik of the Clarke Institute.

Correspondence should be addressed to Professor Louis J. DeFelice, Department of Pharmacology, Vanderbilt University Medical Center, Nashville, TN 37232-6600.

Copyright (C) 1997 Society for Neuroscience $0270-6474 / 97 / 103401-11 \$ 05.00 / 0$
Serotonin uptake has been characterized by radiolabeled 5HT flux (Rudnick, 1996). Based on this method, Rudnick and Clark (1993) modeled mammalian SERTs as electroneutral with stoichiometry: $\mathrm{Na}^{+} / \mathrm{Cl}^{-} / 5 \mathrm{HT}^{+}$and $\mathrm{K}^{+}$countertransported. This process is apparently voltage-independent (Rudnick and Nelson, 1978) and does not rely on a K gradient (Nelson and Rudnick, 1979). Although Reith et al. (1989) and Cool et al. (1990) corroborate this result, Kanner and Bendahan (1985) report K-diffusion-potential-stimulated 5HT uptake. Therefore, discrepancies exist concerning the role of voltage in 5HT uptake. In a heterologous expression system, in which Xenopus oocytes were used to express rat SERTs, Mager et al. (1994) observed that 5HT uptake was voltage-independent. In this system, it was also shown that 5 to $12 \mathrm{Na}^{+}$ions could "escape" into the cell during each transport cycle, thus generating an ionic current in excess of the predicted electroneutrality of coupled transport in mammalian SERTs.

Corey et al. (1994) and Demchyshyn et al. (1994) cloned the Drosophila serotonin transporter (dSERT) and studied its ionic dependence and pharmacological characteristics. In Xenopus oocytes expressing dSERT, Corey et al. report that 5HT uptake depends on $\mathrm{Na}$ and $\mathrm{Cl}$. Changing the membrane from -40 to -80 $\mathrm{mV}$ increased 5HT uptake by a factor of three. Moreover, the induced currents in dSERT are larger than those in mammalian SERTs under comparable conditions. It thus appeared possible to investigate the channels underlying the dSERT currents and to study their relationship to voltage-dependent uptake in the same cells. We have combined radioactive flux assays and voltage-clamp and fluctuation analysis to quantify the relationship between uptake and membrane potential. These data also provide a measure 


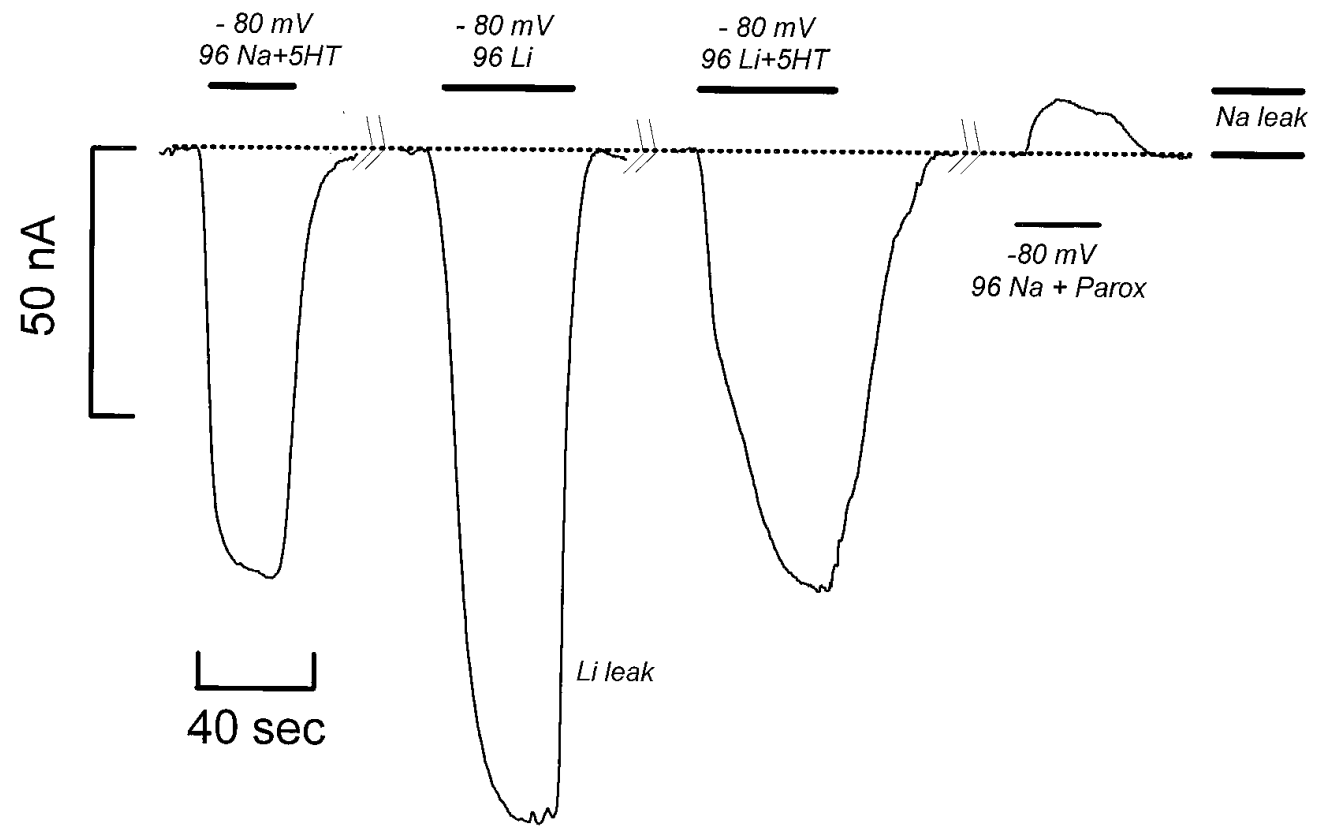

Figure 1. Serotonin induces paroxetinesensitive currents in dSERT-cRNAinjected oocytes. Oocytes injected with cRNA for the Drosophila serotonin transporter (dSERT) have a 5HT-induced inward current when oocytes are clamped to negative potentials. The holding potential in these experiments was $-80 \mathrm{mV}$. In 96 $\mathrm{mM} \mathrm{NaCl}, 5 \mu \mathrm{M} 5 \mathrm{HT}$ induces current in oocytes injected with Drosophila serotonin transporter cRNA. Serotonin induces no current in uninjected or mock-injected oocytes (data not shown). Substituting $\mathrm{Na}$ with $\mathrm{Li}$ in the absence of $5 \mathrm{HT}$ stimulates a large paroxetine-sensitive inward current (the $\mathrm{Li}$ leak). In $96 \mathrm{~mm} \mathrm{LiCl} \mathrm{solution,} 5 \mu \mathrm{M}$ 5HT partially blocks the leak current. The addition of $1 \mu \mathrm{M}$ paroxetine, a 5HTtransporter inhibitor, to the Ringer's solution perfusion medium decreases the holding current. We obtained a similar decrease using desipramine $(10 \mu \mathrm{M})$ or substituting $\mathrm{NaCl}$ with CholineCl (data not shown).

of 5HT translocation per 5HT-induced channel opening, and they are consistent with two models of the transporter. In one model, hundreds of coupled transport cycles must occur for each channel opening. In this case, voltage-dependent 5HT uptake resides in the transport cycle, and 5HT accumulates by coupling to the gradients of the co-transported ions. A second model envisions that 5HT gates a channel permeable to small inorganic ions and to $5 \mathrm{HT}$. In this case, electrochemical gradients acting on 5HT cations explain voltage-dependent uptake. If the transporter is a 5HT channel and no coupling occurs in the pore, 5HT can accumulate against its chemical gradient only as predicted by the voltage gradient. We evaluate these predictions and further compare the two models in the Discussion.

\section{MATERIALS AND METHODS}

Electrophysiology. We performed voltage-clamp experiments using the two-electrode voltage-clamp technique. A GeneClamp 500 (Axon Instruments, Foster City, CA), band-limited at $2000 \mathrm{~Hz}$, was used to measure current. The recorded current was stored for analysis on videotape (Panasonic, Secaucus, NJ). Voltage-clamp electrodes filled with $3 \mathrm{M} \mathrm{KCl}$ solution, were pulled using a programmable puller (Sachs-Flaming, P87, Sutter Instruments, Novato, CA). The voltage steps ranged from -140 to $40 \mathrm{mV}$ and lasted $500 \mathrm{msec}$. All the data were obtained at room temperature. The recording solution was as follows (in $\mathrm{mM}$ ): $\mathrm{Na}^{+}$Ringer's solution $\left(96 \mathrm{NaCl}, 2 \mathrm{KCl}, 5 \mathrm{MgCl}_{2}, 5 \mathrm{HEPES}\right.$, and $0.6 \mathrm{CaCl}_{2}$ ); the ionic substitutions were $\mathrm{NMDG}^{+}$for $\mathrm{Na}^{+}, 96 \mathrm{NMDGCl} ; \mathrm{Li}^{+}$for $\mathrm{Na}{ }^{+}, 96 \mathrm{LiCl}$; acetate for $\mathrm{Cl}^{-}$, acetate salts of $\mathrm{Na}^{+}$. Bath solutions were changed by a gravity pump at a rate of $1 \mathrm{ml} / \mathrm{min}$.

$\left[{ }^{3} H\right] 5 H T$ flux. Current measurements and flux assays were measured simultaneously while perfusing the voltage-clamped oocytes with $1.8 \mu \mathrm{M}$ 5HT (200 nм [ $\left.{ }^{3} \mathrm{H}\right] 5 \mathrm{HT}, 100 \mathrm{Ci} / \mathrm{mmol}$, Amersham, Arlington Heights, IL) final concentration. The experiments were terminated by washing the oocytes in Ringer's solution three times over a period of $20 \mathrm{sec}$, and then solubilized in $1 \%$ SDS. The $5 \mathrm{HT}$ uptake was determined by liquid scintillation counting. We performed control experiments by injecting the oocytes with 100 pmol of $\left[{ }^{3} \mathrm{H}\right] 5 \mathrm{HT}$, and measuring the release of radiolabeled 5HT during a 1 min experimental time. During this time, no significant efflux of $\left[{ }^{3} \mathrm{H}\right] 5 \mathrm{HT}$ was detected. Furthermore, in uninjected oocytes, nonspecific uptake, during $1 \mathrm{~min}$ experimental time, was not voltage-dependent in the range of potentials studied and was $<4 \%$ of the specific uptake at $-20 \mathrm{mV}$.

Oocytes and $c R N A$. The $2.3 \mathrm{~kb}$ dSERT BglII fragment was blunt-ended and cloned into the blunt-ended BamHI site of pBluescript $\mathrm{KS}^{+}$plasmid (Stratagene, La Jolla, CA) downstream of the T7 promotor (Demchyshyn et al., 1994). cRNA was transcribed in vitro using the Ambion mMessage mMachine T7 In Vitro Transcription Kit. Stage V and VI defolliculated oocytes were injected with $42 \mathrm{nl}(1 \mu \mathrm{g} / \mu \mathrm{l})$ of dSERT cRNA and then incubated at $18^{\circ} \mathrm{C}$ in Ringer's solution, $\mathrm{pH}$ 7.6, supplemented with $1 \%$ penicillin-streptomycin stock $(10,000 \mathrm{U} / \mathrm{ml}$, Gaithersburg, MD), and 5\% horse serum (Life Technologies) (Quick et al., 1992). Peak expression of dSERT varied from batch to batch ranging from 4 to $9 \mathrm{~d}$.

\section{RESULTS}

\section{HT activates paroxetine-sensitive currents in dSERT-cRNA-injected oocytes}

RNA-injected oocytes display saturable 5HT accumulation, 5HTinduced currents, and transporter-associated but 5HTindependent currents that are not present in uninjected controls. We begin with a description of the 5HT-induced and 5HTindependent (leak) currents. In $96 \mathrm{~mm} \mathrm{NaCl}$, oocytes injected with cRNA for dSERT exhibited an inward current when held at negative potentials and $5 \mathrm{HT}$ was added to the bath. In the experiment shown in Figure 1, we held an oocyte at $-80 \mathrm{mV}$ and added $5 \mu \mathrm{M}$ 5HT to the perfusing Ringer's solution. We refer to the difference between the holding current and the current in the presence of 5HT as the 5HT-induced current. Uninjected or mock-injected oocytes have no 5HT-induced current (data not shown). The 5HT-induced current typically reaches a steady-state in $<2$ sec after $5 \mathrm{HT}$ application (reflecting primarily the speed of the perfusion system). In RNA-injected oocytes, replacing $\mathrm{NaCl}$ with $\mathrm{LiCl}$ activates an inward current at $-80 \mathrm{mV}$ with no $5 \mathrm{HT}$ present; in this experiment, the inward current in $96 \mathrm{~mm} \mathrm{Li}$ was $142 \%$ of the 5 HT-induced current in $96 \mathrm{~mm} \mathrm{Na}$. We refer to this as the Li leak current, meaning the transporter-associated current generated in the presence of $\mathrm{Li}$ and in the absence of 5HT. The Li leak is not seen in uninjected oocytes. In agreement with other studies, adding $5 \mathrm{HT}$ reduced the Li leak by $30 \pm 7 \%$ (6 oocytes). Simultaneous application of 5HT $(5 \mu \mathrm{M})$ and $\mathrm{LiCl}(96 \mathrm{~mm})$ induced an inward current that was $70 \pm 17 \%$ (6 oocytes) of the Li leak current. This suggests that the Li leak current does not correlate with $5 \mathrm{HT}$ transport, and Figure $3 A$ shows that in the presence of Li and 5HT, there is no 5HT transport. Finally, we note that $1 \mu \mathrm{M}$ paroxetine reduces the $5 \mathrm{HT}$-induced current $90-100 \%$ and the Li leak current by $70-80 \%$; paroxetine has no 


\section{I/Imax}

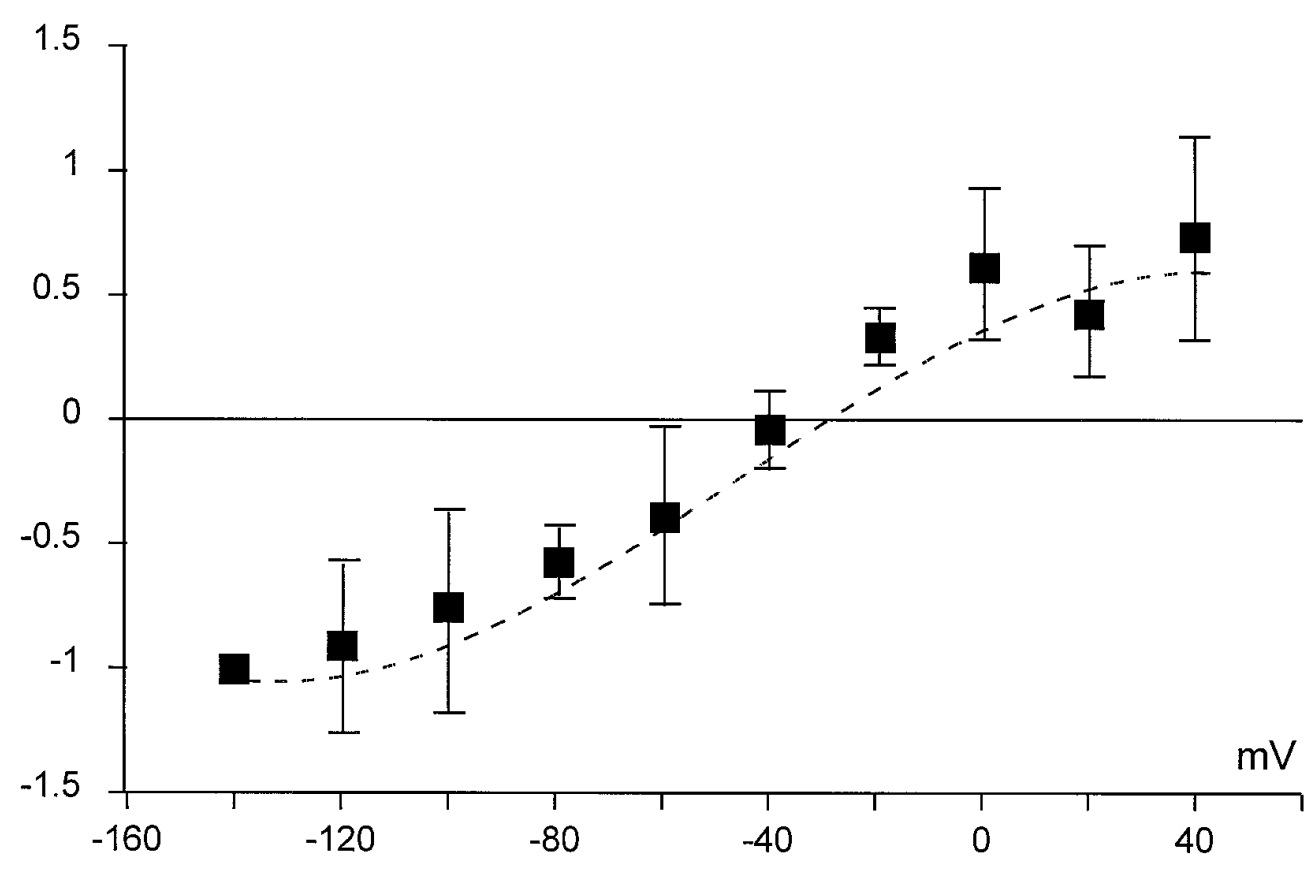

Figure 2. Current-voltage relationship of $\mathrm{Na}$ leak current. Steady-state $I-V$ curve for $\mathrm{Na}$ leak current in Ringer's solution (96 mm Na). The membrane potential was stepped for $500 \mathrm{msec}$ between -140 and $+40 \mathrm{mV}$ from a holding potential of $-40 \mathrm{mV}$. After adding $10 \mu \mathrm{M}$ desipramine to the perfusion medium, the current decreased to a new steady-state value at each voltage. We define leak current as the difference between the background current before adding desipramine and the current in the presence of desipramine. Data were normalized at $-140 \mathrm{mV}$ (4 oocytes). The Na leak current at $-140 \mathrm{mV}$ has an average value of $-9.05 \pm 5.2 \mathrm{pA}$, $\sim 10 \%$ of the $5 \mathrm{HT}$-induced current at this potential. effect on uninjected oocytes, thus both categories of current are associated with the presence of dSERT in the membrane.

Although we have not further characterized the leak, the presence of a transporter-associated leak pathway most evident in $\mathrm{Li}$ solutions raises the possibility of a similar pathway in Na solutions, in which we perform all experiments below. Indeed, Figure 1 shows that in $96 \mathrm{~mm} \mathrm{NaCl}$, and in the absence of 5HT, $1 \mu \mathrm{M}$ paroxetine reduces the holding current in RNA-injected oocytes. There is no similar effect in uninjected oocytes. We obtain approximately the same change in holding current with $1 \mu \mathrm{M}$ paroxetine, with $10 \mu \mathrm{M}$ desipramine, or by substituting $\mathrm{NaCl}$ with CholineCl. We refer to the paroxetine- or desipramine-revealed current as the $\mathrm{Na}$ leak current, implying the transporterassociated current in the presence of $\mathrm{Na}$, but in the absence of 5HT. This does not imply, as the name might suggest, that the $\mathrm{Na}$ leak current is carried by Na. Indeed, we have not characterized the $\mathrm{Na}$ leak with regard to the permeating ions. Rather, we seek to minimize the leak current by working near its reversal potential, which we measure in Figure 2.

\section{Current-voltage relationship of $\mathrm{Na}$ leak current}

Figure 2 shows the average current-voltage relationship of the leak current (96 mm Na, no 5HT) obtained from RNA-injected oocytes. We held the oocytes at $-40 \mathrm{mV}$ and stepped the voltage between -140 and $40 \mathrm{mV}$ in $20 \mathrm{mV}$ increments, measuring the currents in the steady state. The Na leak current is defined as the difference between the control current $(96 \mathrm{~mm} \mathrm{Na}$, no desipramine) and the current after adding desipramine (96 mM Na, $10 \mu \mathrm{M}$ desipramine). Desipramine $(10 \mu \mathrm{M})$ has no effect on uninjected oocytes. Within the same batch of oocytes, $\mathrm{Na}$ leak currents are $\sim 10 \%$ (-9.02 $\pm 5.2 \mathrm{nA}, 4$ oocytes) of 5HT-induced current $(-89.7 \pm 29 \mathrm{nA}, 4$ oocytes) at $-140 \mathrm{mV}$. We fit the experimental points in Figure 2 (normalized to $-140 \mathrm{mV}$ ) with a cubic polynomial using a nonlinear least-squares procedure, obtaining $V_{\text {rev }}$ $=-23 \mathrm{mV}$. Fitting a straight line to the four data points surrounding zero current in Figure 2 gives a reversal of $-26 \mathrm{mV}$. The
Nernst potentials for $\mathrm{K}, \mathrm{Cl}$, and $\mathrm{Na}$ in native oocytes are, respectively, -95, -28, and $61 \mathrm{mV}$ (Dascal, 1987; Costa et al., 1989). Although the leak $V_{\text {rev }}$ is near the literature value of the $\mathrm{Cl}$ reversal potential, we have not investigated the ion selectivity of the leak in RNA-injected oocytes. We reveal approximately the same magnitude of leak current at $-80 \mathrm{mV}$ by substituting $\mathrm{Na}$ with choline (see above), indicating that at negative potentials, $\mathrm{Na}$ may be a major carrier. (For additional discussion of the leak current in hSERT, see Mager et al., 1994.) In this article, we merely use the empirical value of the reversal potential to reduce the leak when determining the elementary event underlying 5HTinduced currents.

\section{lonic dependence of $5 \mathrm{HT}$ uptake and 5HT-induced current}

To verify the Xenopus oocytes expression system for studying the electrophysiological characteristics of dSERT, we studied the ionic selectivity of $\left[{ }^{3} \mathrm{H}\right] 5 \mathrm{HT}$ uptake to compare with previous studies (Corey et al., 1994). Levels of expression were similar in oocytes from the same injection batch, even though they differed significantly from batch to batch. A marked batch deviation also exists in the number of days that the oocytes require to reach the peak expression level (between 4 and $9 \mathrm{~d}$ ). For the uptake measurements presented in Figures 3 and 4 , the oocytes were not impaled for voltage clamp. Figure 3 shows the $\mathrm{Na}$ dependence of 5HT uptake and 5HT-induced current. The oocytes were incubated in a $180 \mu \mathrm{l}$ bath, and 5HT was added to the medium solution and briefly stirred to reach $1.8 \mu \mathrm{M}$ final concentration. The solution contained a final concentration of $200 \mathrm{~nm}\left[{ }^{3} \mathrm{H}\right] 5 \mathrm{HT}$. An incubation time of $5 \mathrm{~min}$ was allowed before beginning the uptake measurements. The uptake velocities that we obtained in our expression system are in approximate agreement with Corey et al. (1994), although as mentioned, considerable variability exists from batch to batch. Complete replacement of $\mathrm{Na}$ with either Li or NMDG reduced the uptake by an average of $81.5 \pm 10 \%$ and $78 \pm 17 \%$, 


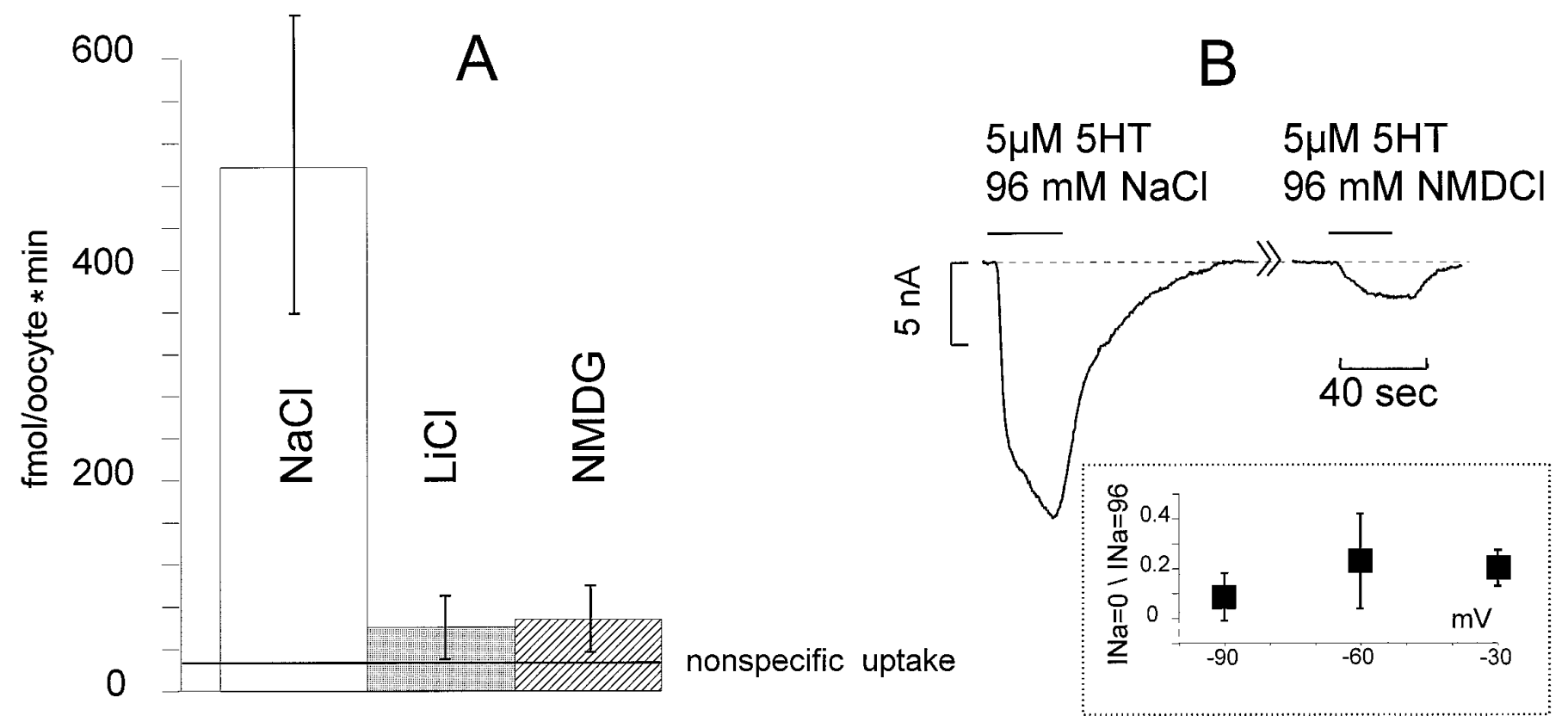

Figure 3. Na dependence of $\left[{ }^{3} \mathrm{H}\right] 5 \mathrm{HT}$ uptake and 5HT-induced current. $A$, 5HT uptake was measured after 5 min incubation with $200 \mathrm{~nm}\left[{ }^{3} \mathrm{H}\right] 5 \mathrm{HT}$. To assess Na-dependent uptake, the standard Ringer's solution was modified by replacing $\mathrm{NaCl}$ with $\mathrm{LiCl}$ or NMDG-Cl to maintain osmolarity. In the absence of $\mathrm{Na}, 5 \mathrm{HT}$ uptake is strongly reduced in three batches of oocytes (4 oocytes for each ion replacement). Nonspecific uptake in uninjected oocytes was $<8 \%$ of the blockable uptake. $B$, The 5HT-induced current depends on the external Na concentration. 5HT was held constant at a saturating concentration $(5 \mu \mathrm{M})$ (see Fig. 6), and the membrane potential was held at $-30 \mathrm{mV}$. The substitution of $\mathrm{NaCl}$ with $\mathrm{NMDG}-\mathrm{Cl}$ reduces the steady-state current at this potential. The inset shows the ratio of the transporter current obtained in $0 \mathrm{mM} \mathrm{NaCl}+5 \mu \mathrm{M} 5 \mathrm{HT}$ to the current obtained in Ringer's solution $+5 \mu \mathrm{M} 5 \mathrm{HT}$ at different voltages.

respectively (three different batches, 3 to 5 oocytes for each $\mathrm{Na}$ replacement). Figure $3 A$ shows the effect of Na substitution on $5 \mathrm{HT}$ uptake for a representative batch. Replacing Na reduces 5HT uptake to nonspecific levels seen in uninjected oocytes. Figure $3 B$ shows 5HT-induced current obtained after applying $5 \mu \mathrm{M} 5 \mathrm{HT}$ to an oocyte held at $-30 \mathrm{mV}$. A comparison of $B$ and $A$ is not strictly valid, because the oocytes in $A$ were not voltage-clamped; $-30 \mathrm{mV}$ was selected, because it is near the resting potentials of RNA-injected oocytes, which tend to have fewer negative resting potentials than uninjected oocytes. Nevertheless, we compare $A$ and $B$ to show that when the oocytes used for flux analysis have not been impaled, there is still a qualitative correlation between the ionic dependence of uptake and the ionic dependence of the transmitter-induced current. The substitution of Na with NMDG reduced the 5HT-induced current by an average of $80 \pm 7 \%$ ( 4 oocytes), in approximate agreement with the reduction in uptake. The percent reduction that was induced by $\mathrm{Na}$ exchange is not strongly voltagedependent in the range of -90 to $-30 \mathrm{mV}$ (inset, 4 to 6 oocytes for each point). Figure $4 A$ illustrates that replacing $\mathrm{Cl}$ with acetate lowers $5 \mathrm{HT}$ uptake by $76 \pm 7 \%$ (four batches, 4 to 5 oocytes per batch). Figure $4 B$ shows 5 HT-induced current obtained after applying $5 \mu \mathrm{M} 5 \mathrm{HT}$ to an oocyte held at -30 $\mathrm{mV}$. The substitution of $\mathrm{Cl}$ with acetate reduced the $5 \mathrm{HT}$ induced currents to an average of $32 \pm 20 \%$ ( 3 oocytes). The reduction in induced current by $\mathrm{Cl}$ exchange is voltageindependent in the range -90 to $-30 \mathrm{mV}$ (inset, 4 to 6 oocytes for each point). We interpret the antagonist-block and ionreplacement data for $\mathrm{Na}$ and $\mathrm{Cl}$ as indicative of the coupling between 5HT uptake and 5HT-induced current. However, another explanation for the observed differences between $A$ and $B$ in Figures 3 and 4 is that nominally $\mathrm{Na}$ - or $\mathrm{Cl}$-free solutions may be contaminated by these ions leaking from the oocyte through channels or pumps not associated with the transporter. We have not attempted protocols that would eliminate such buildup.

\section{Voltage and concentration dependence of the 5HT-induced current}

To investigate the 5HT dependence and voltage dependence of the induced current, the level of substrate in the bath was increased incrementally from 0 to $10 \mu \mathrm{M}$ at three voltages between -100 and $-60 \mathrm{mV}$. At a fixed voltage, the amplitude of the current saturates with increasing 5HT concentration. Normalizing to the current obtained at $10 \mu \mathrm{M} 5 \mathrm{HT}$, the data were fit by nonlinear regression to the equation:

$$
I=I_{\max }[5 \mathrm{HT}]^{\mathrm{n}} /\left(K_{\mathrm{m}}^{\mathrm{n}}+[5 \mathrm{HT}]^{\mathrm{n}}\right),
$$

which gave ( 3 oocytes for each voltage) for $-60 \mathrm{mV}, K_{\mathrm{m}}=1.69 \pm$ $0.24 \mu \mathrm{M}$ and $n=1.38 \pm 0.19$; for $-80 \mathrm{mV}, K_{\mathrm{m}}=0.8 \pm 0.12 \mu \mathrm{M}$ and $n=1.32 \pm 0.25$; for $-100 \mathrm{mV}, K_{\mathrm{m}}=1.16 \pm 0.23 \mu \mathrm{M}$ and $n=$ $0.95 \pm 0.17$. The average values are $K_{\mathrm{m}}=1.21 \mu \mathrm{M}$ and $n=1.21$. $K_{\mathrm{m}}$ and $n$ were also obtained by pooling the experiments. In this case, $K_{\mathrm{m}}=1.26 \pm 0.20 \mu \mathrm{M}$ and $n=1.19 \pm 0.19$. We conclude that there is no significant difference between affinity constants or Hill coefficients in the range of -100 to $-60 \mathrm{mV}$. Thus, the shape of the $I(V)$ curve in this range is unlikely to be influenced by $K_{\mathrm{m}}$ measured for 5HT titration. However, because we have not measured $K_{\mathrm{m}}$ for $\mathrm{Na}$ or $\mathrm{Cl}$, we cannot eliminate voltage-dependent binding or variable stoichiometry as possible explanations of voltage-dependent uptake.

\section{HT uptake depends on voltage}

The comparison between uptake and induced current demonstrated in Figures 3 and 4 suggests that they are associated 


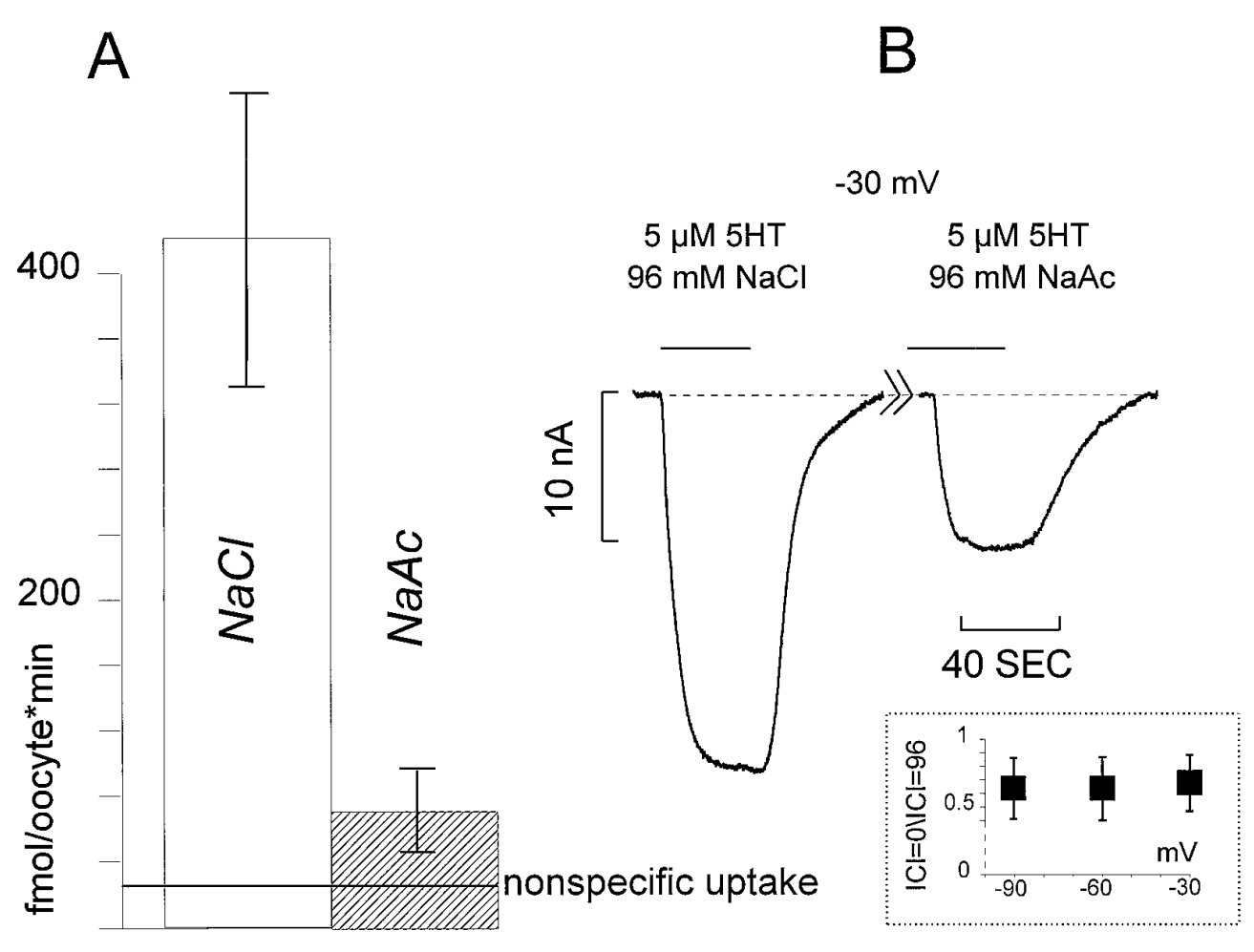

Figure 4. $\mathrm{Cl}$ dependence of $\left[{ }^{3} \mathrm{H}\right] 5 \mathrm{HT}$ uptake and 5HT-induced current. $A$, 5 HT uptake was measured after 5 min incubation with $200 \mathrm{~nm}\left[{ }^{3} \mathrm{H}\right] 5 \mathrm{HT}$. To assess Cl-dependent uptake, the standard Ringer's solution was modified by replacing $\mathrm{NaCl}$ with $\mathrm{Na}$-acetate to maintain osmolarity. In the absence of $\mathrm{Cl}$, $5 \mathrm{HT}$ uptake is strongly reduced in three batches of oocytes ( 4 oocytes for each ion replacement). In experiments performed without external $\mathrm{Cl}$, 5HT uptake was strongly reduced. $B$, The oocytes were clamped at $-30 \mathrm{mV}$ and perfused with Ringer's solution and $5 \mu \mathrm{M} 5 \mathrm{HT}$. When the external $\mathrm{Cl}$ was exchanged with acetate, the current decreased. The inset shows the ratio of the transporter current obtained in solution containing no $\mathrm{Cl}+5 \mu \mathrm{M} 5 \mathrm{HT}$ to the current obtained in Ringer's solution $+5 \mu \mathrm{M} 5 \mathrm{HT}$ at different voltages. events. To investigate the voltage dependence of uptake, we initially performed radiolabeled 5HT flux experiments on batches of oocytes expressing different levels of transporter. We held oocytes at $-30 \mathrm{mV}$ and perfused them with $1.8 \mu \mathrm{M}$ $5 \mathrm{HT}(100 \mathrm{Ci} / \mathrm{mmol})$. After $5 \mathrm{~min}$, the oocytes were washed, lysed, and assayed for accumulated 5HT. This procedure was repeated for another set of oocytes from the same batch, but held at $-100 \mathrm{mV}$. We duplicated these experiments for three batches, including one batch with low expression. These data are shown in Figure 5; the shading of the bar identifies a particular batch. Even including a batch with low levels of uptake, the average accumulation of 5HT across batches was $2.24 \pm 0.8$ times higher at -100 than at $-30 \mathrm{mV}$ ( 3 or 4 oocytes in each batch). The same pattern exists at lower 5 HT concentrations. This is shown in the inset, in which we used $0.1 \mu \mathrm{M}$ 5HT and obtained $3.36 \pm 0.9$ times higher 5HT uptake by dSERT at -100 than at $-30 \mathrm{mV}$ (one batch, 3 oocytes per voltage). These data are in approximate agreement with Corey et al., who performed similar experiments at -40 and $-80 \mathrm{mV}$. From our data, we conclude that negative voltages stimulate 5HT uptake, and this stimulation is approximately independent of the level of expression or the concentration of 5HT.

\section{Number of ions translocated with $5 \mathrm{HT}$ varies with membrane potential}

Figure 5 demonstrates that negative voltages stimulate 5HT uptake in dSERT; however, the protocol prohibits alteration of voltage in the same cell, because the cells are lysed after each measurement. Furthermore, differences in expression levels force reliance on batch averages to measure uptake as a function of voltage, as in a previous study of dSERT (Corey et al., 1994). We require a method that compares oocytes from different batches, without regard to the level of expression. To achieve this, we measured 5HT uptake and 5HT-induced current simultaneously for single oocytes held at a specific potential. Each oocyte was voltage-clamped and bathed for $50 \mathrm{sec}$ in $\left[{ }^{3} \mathrm{H}\right]$-labeled $1.8 \mu \mathrm{M} 5 \mathrm{HT}$ Ringer's solution. The integration of the 5HT-induced current measures the total charge movement $Q$ at a particular voltage. We also measured $Q_{5 \mathrm{HT}}$ from the same voltage by scintillation counting of lysed oocytes. The derived quantity $\rho(V)$ is the ratio $Q / Q_{5 \mathrm{HT}}$, which we obtain from different oocytes at different voltages. Thus, $\rho(V)$ is independent of expression level. We distinguish the charge $Q_{5 \mathrm{HT}}$ carried by $5 \mathrm{HT}^{+}$(assuming $5 \mathrm{HT}$ is translocated as a monovalent cation at $\mathrm{pH}=7.6)$ from the charge $Q_{\mathrm{e}}$ carried by other ions. Thus, $Q=Q_{\mathrm{e}}+Q_{5 \mathrm{HT}}$. If each transporter carries the same proportion of 5HT and non-5HT charge, then:

$$
\rho=\left(q_{\mathrm{e}}+q_{5 \mathrm{HT}}\right) / q_{5 \mathrm{HT}},
$$

where $q_{\mathrm{e}}$ and $q_{5 \mathrm{HT}}$ represent charge movements through individual transporters. Thus, $\rho(V)$ is a microscopic property of individual transporters, and $1 / \rho$ represents the fraction of charge carried by $5 \mathrm{HT}$. Figure $6 A$ plots $\rho(V)$ as a function of voltage for data from 54 oocytes (4 to 11 oocytes for each point). We find translocated charge in excess of 5HT accumulation, and this ratio is voltage-dependent. The minimum ratio is $\rho=17 \pm 3$ at $20 \mathrm{mV}$, and the maximum ratio is $\rho=67 \pm 15$ at $-80 \mathrm{mV}$ (mean $\pm \mathrm{SD}$ ). For example, at $-80 \mathrm{mV}, 5 \mathrm{HT}$ induces the translocation of $67 e$ for every 5HT molecule that passes through dSERT ( $e=1$ electronic charge unit). We fit the average points (solid squares) and the upper and lower SDs (bars) with a cubic polynomial. These fits are the solid curves in Figure $6 A$. To estimate the absolute current carried by the movement of $5 \mathrm{HT}^{+}$alone, we now compare $\rho(V)$ with $I(V)$ curves measured separately for particular oocytes. Figure $6 B$ shows the $I(V)$ curve for 5HT-induced currents from the same batch. The voltage was stepped for $500 \mathrm{msec}$ to -140 to 40 $\mathrm{mV}$ in $20 \mathrm{mV}$ increments, holding the oocyte at $-40 \mathrm{mV}$, and currents were measured between 400 and $500 \mathrm{msec}$ after the initiation of the test pulse. We defined the $I(V)$ curve by subtracting the control current (no 5HT) from the 5HT-induced current. 


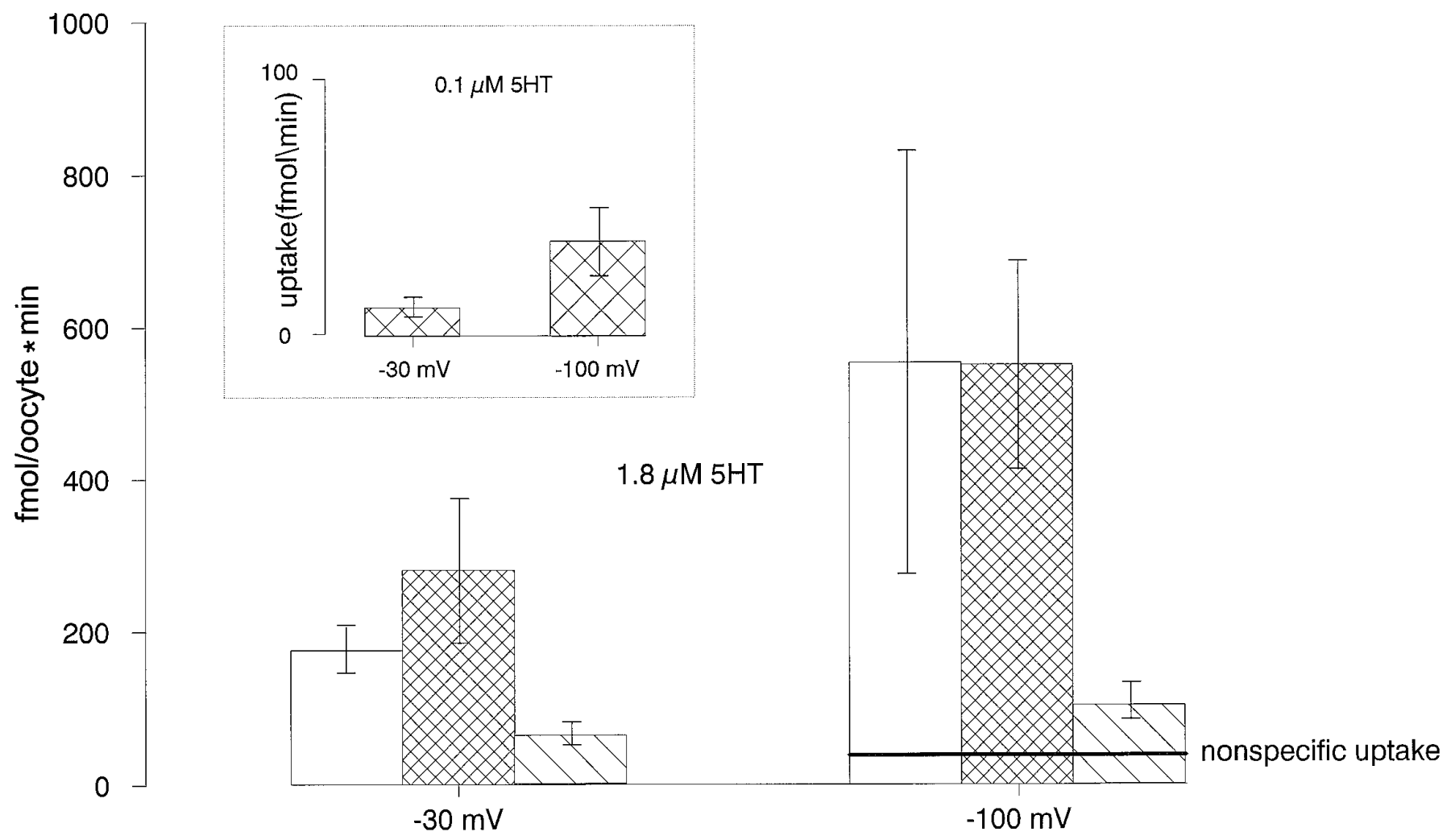

Figure 5. Membrane potential regulates 5HT uptake. In these experiments, the membrane potential was held at -30 or $-100 \mathrm{mV}$ while the oocytes were exposed for $5 \mathrm{~min}$ to $1.8 \mu \mathrm{M} 5 \mathrm{HT}$ or $0.1 \mu \mathrm{M} 5 \mathrm{HT}$ (inset). Uptake in oocytes not under voltage clamp was measured as in Figures 3 and 4 . In three batches of oocytes (at least 3 oocytes per batch per voltage), we found that the uptake of 5HT is significantly increased at the negative potential. Each bar represents a different batch, and the variation in absolute magnitude reflects different levels of expression.

The $I(V)$ curve displays inward rectification and does not reverse for voltages up to $40 \mathrm{mV}$, in agreement with Corey et al. (1994). These representative oocytes had nearly equivalent expression levels, judging by the small SD in 5HT-induced currents. We fit these experimental points (solid triangles) with the quadratic polynomial. We may also write $\rho$ as the ratio $\rho=I / I_{5 \mathrm{HT}}$, because $Q$ and $Q_{5 \mathrm{HT}}$ are measured in the same time interval. The current carried by $5 \mathrm{HT}$ in these oocytes is then given by:

$$
I_{5 \mathrm{HT}}(V)=I(V) / \rho(V) .
$$

Note that in this formula, $I(V)$ and $\rho(V)$ come from two different data sets; $I(V)$ varies with expression level and is measured for an individual oocyte, and $\rho(V)$ is independent of expression level in the range we have studied and is measured one voltage at a time for separate oocytes. The result of this division appears in Figure $6 C$. The solid line is the ratio of averages from $A$ and $B$ and is the current carried by $5 \mathrm{HT}$ for the oocytes in $B$. The dotted lines in $C$ reflect the same calculation using fits to the SDs in $A$ and $B$. These data are consistent with Figure 5, which shows that 5HT uptake increases at negative voltages.

\section{Number of 5HT molecules translocated per 5HT-induced channel opening}

$I_{5 \mathrm{HT}}$ does not give the relationship between the movement of 5HT and the elementary event underlying the induced current. For this, we must know the charge carried in a typical channel opening, which will enable us to estimate how many $5 \mathrm{HT}$ molecules are translocated per channel event. First note that we may infer from Figure $6 A$ the relative charge translocated per $5 \mathrm{HT}$ molecule. In particular:

$$
\rho-1=q_{\mathrm{e}} / q_{5 \mathrm{HT}} .
$$

This ratio does not indicate the absolute number of charges translocated per transporter event, only the relative number. For example, at $20 \mathrm{mV}, \rho=17$ implies $16 e$ for each $5 \mathrm{HT}$ molecule. If we assume, for example, that one 5HT corresponds to one transporter cycle, we might conclude that $16 e$ translocate/cycle. However, the data are also consistent with $160 e$ moving every 10 cycles, or any other ratio of 16:1. To know the absolute ratio, we need the charge carried by the channels that underlie the current. To estimate this, we measured the mean and the variance of the 5HT-induced currents, as indicated in Figure 7. In these experiments, oocytes were held at $-20 \mathrm{mV}$ to reduce contamination from the $\mathrm{Na}$ leak pathway (see Fig. 2).

From shot noise theory (DeFelice, 1981), the ratio of the variance to the mean is independent of the frequency of events. If a unitary event is approximated by a $\delta$ function, and if the fluctuations caused by the random arrival of such events are measured in a bandwidth $\mathrm{B}$, the ratio of the variance to the mean is given by:

$$
\sigma^{2} / I=2 q B
$$

In this formula, $I$ indicates the 5 HT-induced current, $\sigma^{2}$ is the difference variance in the presence and absence of 5HT, and $q$ is the net charge per shot. From seven experiments similar to that in Figure 7 , we measured $\sigma^{2} / I=2.75 \pm 0.92 \mathrm{pA}$ at $-20 \mathrm{mV}$. The value of $I$ in these experiments ranged between -8.4 and $-25 \mathrm{nA}$, indicating that the level of expression in these oocytes varied 

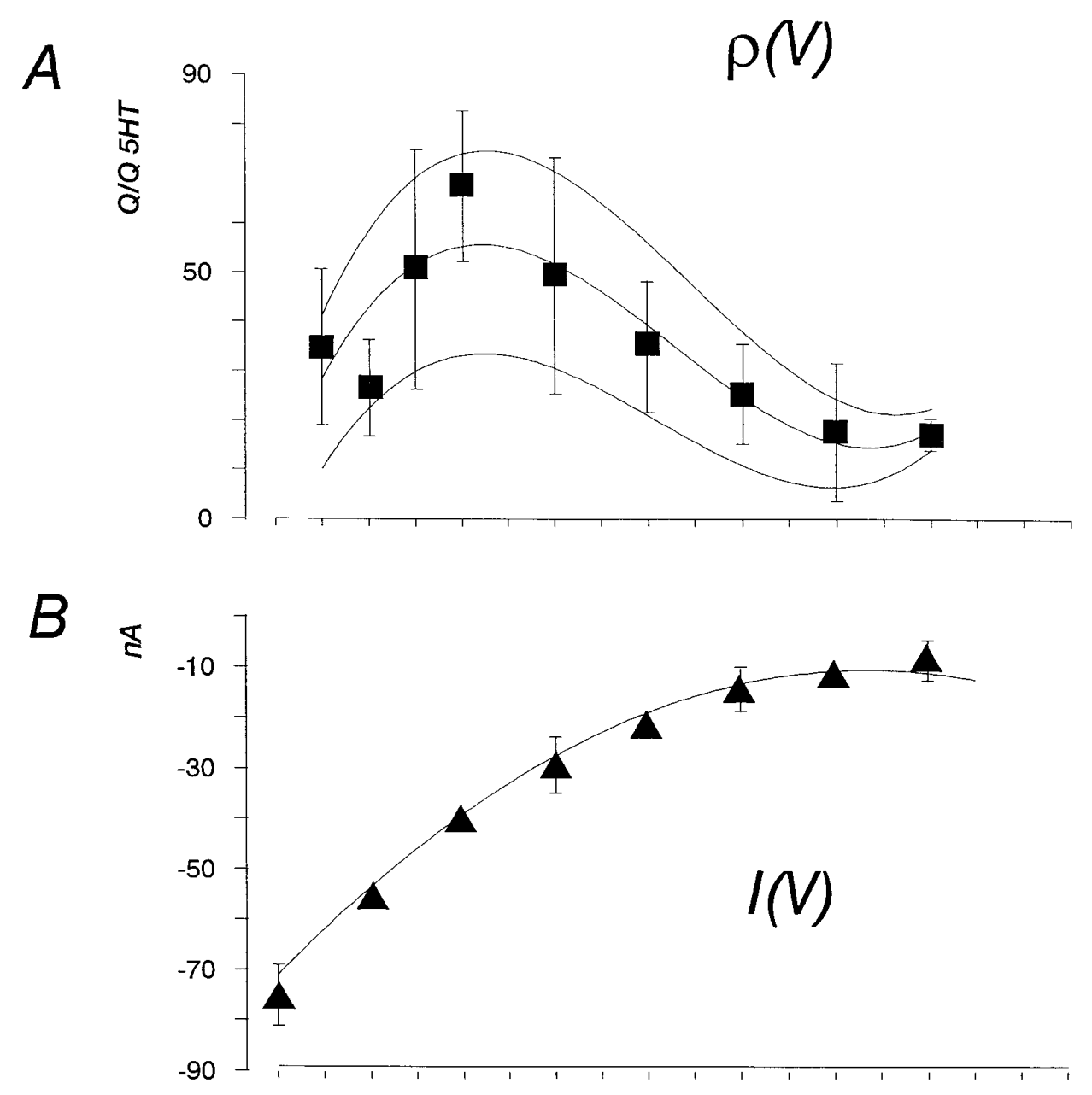

Figure 6. The number of charges translocated per 5HT varies with membrane potential. $A$, Ion translocation and substrate uptake were simultaneously measured during a $50 \mathrm{sec}$ application of $1.8 \mu \mathrm{M} 5 \mathrm{HT}$ at different voltages. The ratio $(\rho)$ of the total charge translocated (obtained by integrating the 5HT-induced current) and the charge measured by the substrate accumulation is voltage-dependent. We fit the average ratio, and the upper and lower SDs, with a thirdorder polynomial $p V=p_{1} V^{3}+p_{2} V^{2}+p_{3} V$ $+p_{4}$ (solid lines). $B$, Currents obtained by applying $1.8 \mu \mathrm{M} 5 \mathrm{HT}$ to the bath perfusion and clamping at different voltages ( 3 oocytes per point from the same batch). The average of the difference currents is plotted against voltage. We fit the experimental points with the quadratic polynomial $I(V)=$ $p_{1} V^{2}+p_{2} V+p_{3}$. $C$, Dividing the absolute currents (the solid line in $B$ ), by $\rho$ (the three solid lines in $A$ ), determines the current carried by $5 \mathrm{HT}$ in these particular oocytes. The solid line represents the average current carried by $5 \mathrm{HT}$ ions as a function of voltage, and the dashed lines represent the SDs.

threefold. Thus, 5HT-induced noise is proportional to the 5HTinduced current in this expression range. No comparable increase in the variance occurs on injecting currents up to $-25 \mathrm{nA}$ in control oocytes. 5HT increases neither the current nor the variance in uninjected control oocytes, and $1 \mu \mathrm{M}$ paroxetine blocks both the 5HT-induced current and the 5HT-induced fluctuations in RNA-injected oocytes, indicating further that the fluctuations are associated with the transporter. In these same oocytes, we also measured $\rho$ at $-20 \mathrm{mV}$, as in Figure $6 \mathrm{~A}$. For the bandwidth between 10 and $1000 \mathrm{~Hz}$, the charge $q$ obtained from $\sigma^{2} / 2 \mathrm{BI}$ has the average value: $q=8250 \pm 2870 e$ ( 7 oocytes). We also determined $q$ by fitting a linear regression to $\sigma^{2} / I=i_{\mathrm{o}}+2 q B$, using four-pole Butterworth filters to vary the upper cutoff between 100 and $1000 \mathrm{~Hz}$. For three oocytes and four values of $B$, 

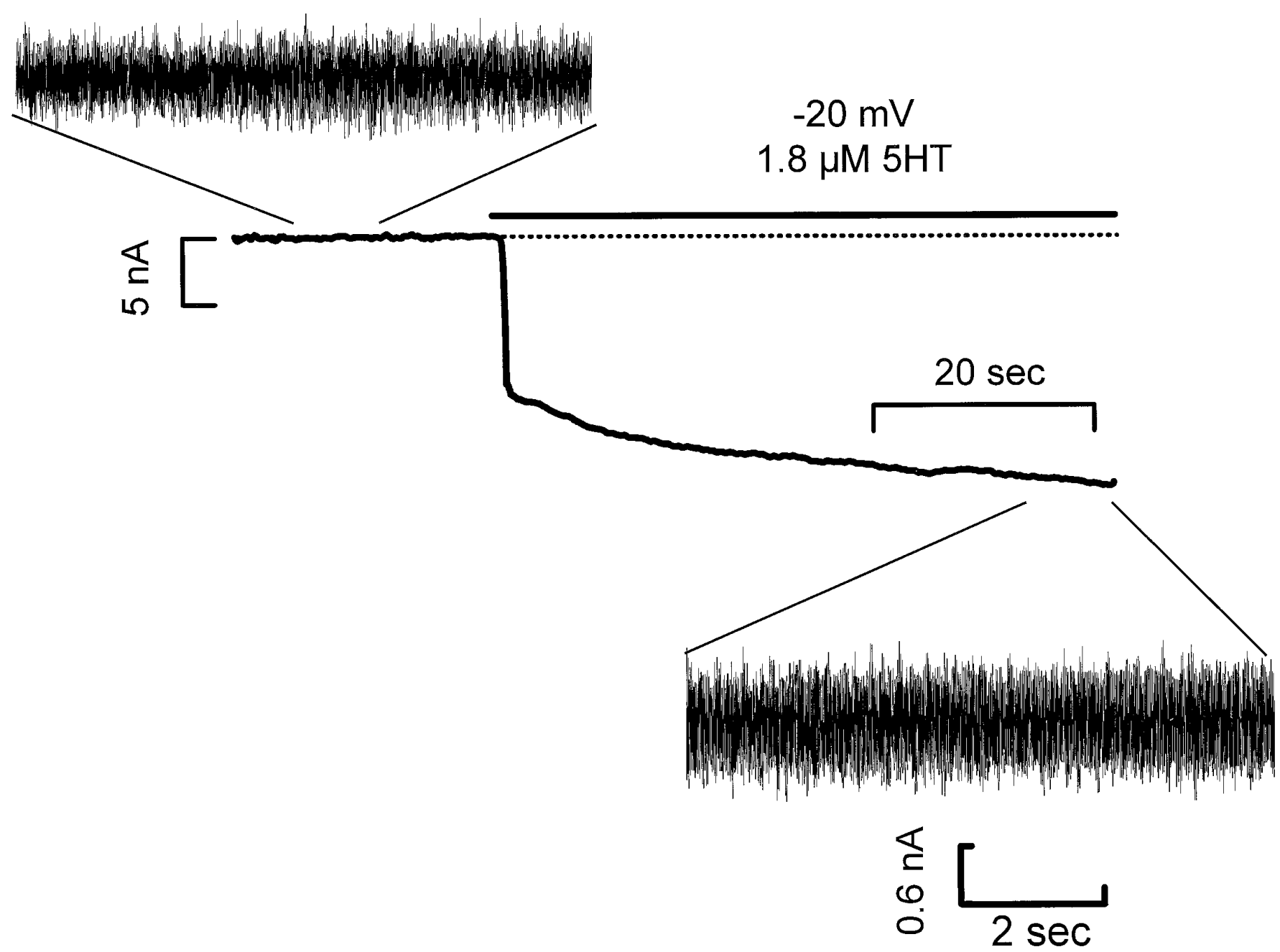

Figure 7. Fluctuation analysis of the 5HT-induced current. The record shows a typical experiment in which the oocyte was held at $-20 \mathrm{mV}$, and $1.8 \mu \mathrm{M}$ serotonin was added to the bath at the indicated time. The insets show the current fluctuations on an expanded scale. The 5HT-induced current is taken as the average current difference at the quasi steady-state level. The 5HT-induced fluctuations are measured as the difference in variance between the two traces (inset), calculated over $16 \mathrm{sec}$ in the bandwidth of $10-1000 \mathrm{~Hz}$.

this plot yielded $i_{\mathrm{o}}=0.102 \pm .12 \mathrm{pA}$ and $2 q=13,510 \pm 1005 e$ $(q=6755 e)$, which is in reasonable agreement with $q=8250 e$ This result implies that the frequency spectrum of the induced noise is approximately flat. In the following discussion, we use the larger value of $q$ obtained from the full bandwidth. The value of $q$ is unexpectedly large and leads to the conclusion that $\sim 500$ transport cycles occur for each channel opening. In the Discussion, we show that relaxing the assumption of the $\delta$ function leads to a similar conclusion. For a model in which 5HT translocation occurs exclusively through coupled transport, $q / \rho$ estimates of the number of cycles $(v)$ per 5HT-induced channel. Dividing $q=8250$ by $\rho=18 \pm 2.7$ (the value obtained at $-20 \mathrm{mV}$ in the oocytes used for fluctuation analysis) gives $458 \pm 159 e$. Assuming that $5 \mathrm{HT}$ is a monovalent cation and assuming one 5HT per cycle imply that $v=458$ cycles. Thus, the combination of flux data and noise analysis provides a novel measure of transporter cycles per channel opening, assuming that coupled transport and so-called uncoupled currents are separate transporter states. We stress that the coupled and uncoupled states are likely to be linked because of similar 5HT and ionic dependence and antagonist sensitivities. These data are also consistent with a model in which transport and channel openings are not separate events. In this case, $q / \rho$ has a different interpretation, that is, the number of 5HT molecules that translocate per channel opening is $q_{5 \mathrm{HT}}=q / \rho$. Below, we use the nominal values: $v$ (or $\left.q_{5 \mathrm{HT}}\right)=500$, and $q=10,000$ when considering the implications of these data for 5HT transport and ion permeation through dSERT.

\section{DISCUSSION}

RNA-injected oocytes display 5HT uptake that is absent in uninjected or mock-injected oocytes, and they have a pronounced 5HT-induced current. The 5HT flux and 5HT-induced current are ion-dependent. Replacing $\mathrm{Na}$ with $\mathrm{Li}$ or NMDG or replacing $\mathrm{Cl}$ with acetate reduces uptake and current, and flux and current are sensitive to paroxetine and desipramine. Moreover, $K_{\mathrm{m}}$ obtained from induced currents are in approximate agreement with $K_{\mathrm{m}}$ for dSERT determined by uptake assays in Xenopus oocytes, for which $K_{\mathrm{m}}=0.637 \mu \mathrm{M}$ (Corey et al., 1994). The value we obtain, $K_{\mathrm{m}}=1.26 \mu \mathrm{M}$, is independent of voltage between -100 and -60 $\mathrm{mV}$. Corey et al. (1994) show that both uptake and current increase with hyperpolarization, in agreement with our results. Comparable ionic dependence, voltage dependence, 5HT and 


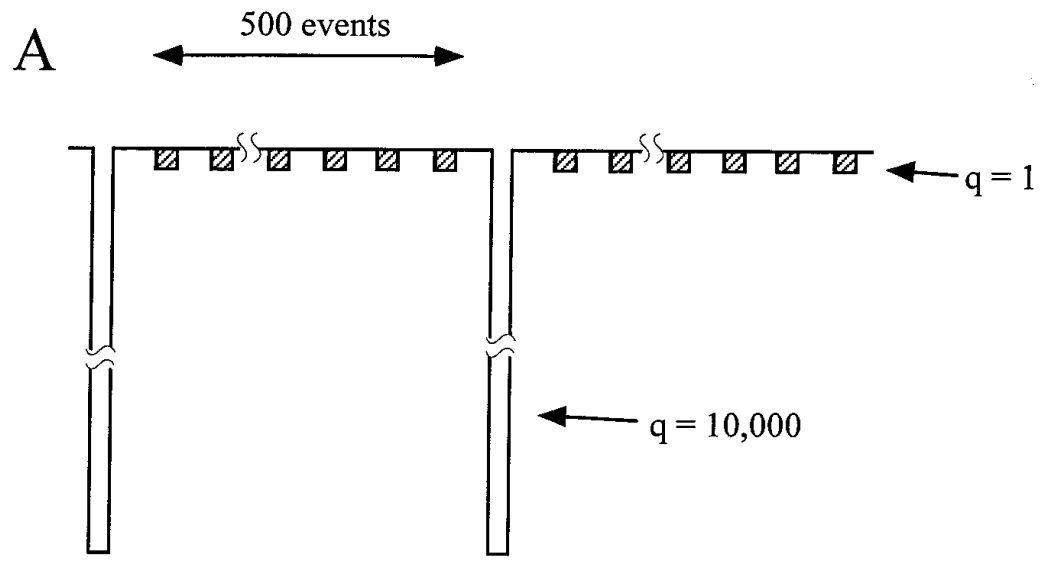

B
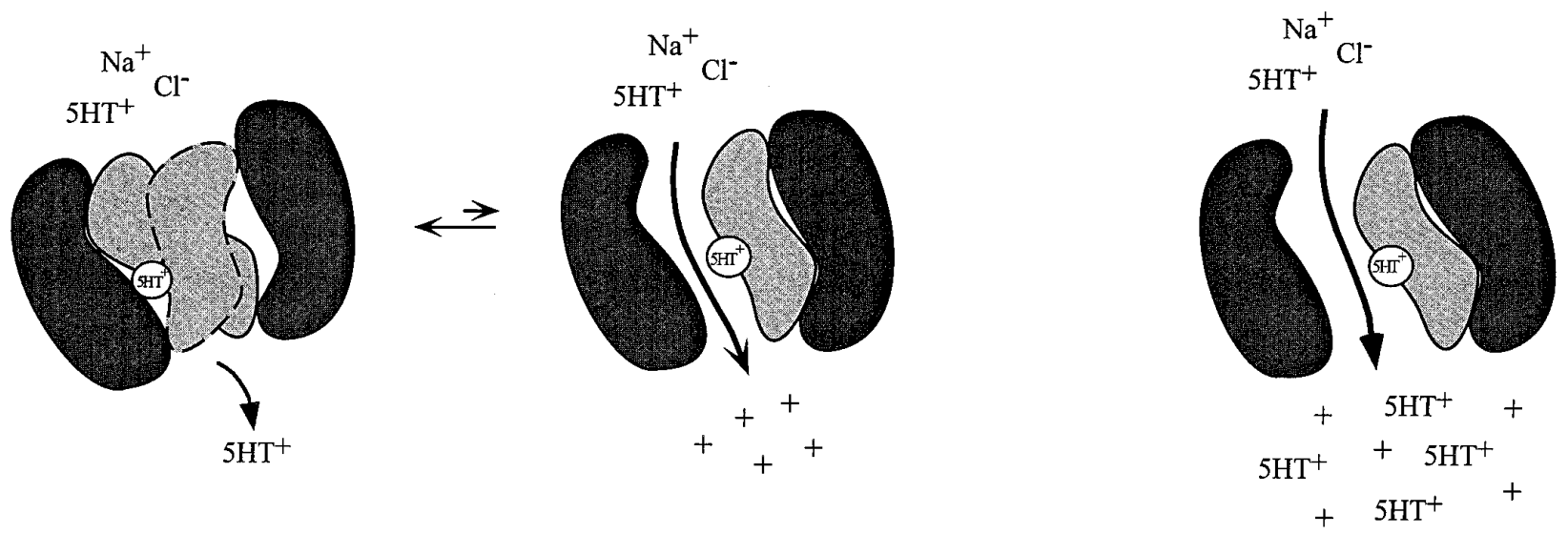

Figure 8. Alternative models of dSERT. In $A$, two classes of events occur. The transporter is either in the coupled mode, in which 5HT translocates in fixed stoichiometric ratio with co-transported ions. On average, once every 500 cycles, a 5HT-gated channel opens, allowing 10,000e to pass through but not $5 \mathrm{HT}^{+}$. In the second model, illustrated in $B, 5 \mathrm{HT}$ gates a channel through which $10,000 e$ pass, $\sim 5 \%$ of which are $5 \mathrm{HT}^{+}$. For simplicity, we have shown only $5 \mathrm{HT}$ binding in $A$ and $B$; obligatory binding of $\mathrm{Na}$ and $\mathrm{Cl}$ ions is implied in both models.

antagonist sensitivities, and $K_{\mathrm{m}}$ values indicate that 5HT flux and 5HT-induced current are coupled mechanisms.

Recent findings from a number of laboratories (see introductory remarks) make it necessary to consider at least three types of current associated with neurotransmitter transporters: (1) channels that open in the absence of transmitter (leak), (2) transmitter-gated channels without transport, and (3) current produced during transmitter translocation. It is simple to isolate the leak current (1) but difficult to separate transmitter-gated current (2) from transmitter-translocation current (3). We have isolated the current carried by the charged neurotransmitter $5 \mathrm{HT}^{+}$and estimated the size of the transmitter-gated channels, eliminating leak pathways by working at the leak-reversal potential. The data have two interpretations. First, the transmittergated channel may represent an ion pathway through which there is no translocation of transmitter. In this case, we have measured the number of transport cycles (which may generate a fraction of the current, depending on stoichiometry) that occur per channel opening (which generate the major current). Note that the ratio $v$ $=$ transport cycles/channel is distinct from ratios published previously ( $\rho=$ charges/translocated transmitter). The results pre- sented here also agree with the combined movement of 5HT and other ions through a 5HT-gated channel that combines 2 and 3 in the same state.

\section{Current carried by leak pathways}

Leak current is defined as transporter-associated current in the absence of transmitter. In mammalian SERTs, 5HT reduces the Li leak ( $\mathrm{LiCl}$ replacing $\mathrm{NaCl}$ ) (Mager et al., 1994), and we observe a similar phenomenon in dSERT. A leak is also present in $\mathrm{NaCl}$, which we reveal by application of paroxetine or desipramine or by the replacement of $\mathrm{Na}$ with choline. The $\mathrm{Na}$ leak exists in the presence of $5 \mathrm{HT}$, but $5 \mathrm{HT}$ partially blocks it. The Na leak is $10 \%$ of the induced current at $-140 \mathrm{mV}$ and reverses near $-20 \mathrm{mV}$. The induced current does not reverse, and we interpret this as large outward leak current compared with outward induced current; thus, plotting (induced current) - (leak) results in net inward current. Using this convention, the inward current positive to the reversal potential of the leak represents 5HT-induced current and, primarily, the outward leak current that is blocked by 5HT. A similar interpretation was made for the dopamine transporter (Sonders et al., 1997). 


\section{The leak current}

We now consider how the leak current affects the measure of $I_{5 \mathrm{HT}}$ and, therefore, our estimate of $v$ or $q_{5 \mathrm{HT}}$. Define Na leak in the absence of $5 \mathrm{HT}$ as $I_{\text {leak }}$, and the comparable pathway in $5 \mathrm{HT}$ as $I^{\prime}{ }_{\text {leak }}$. If 5HT partially blocks $I^{\prime}{ }_{\text {leak }}$, then $I^{\prime}{ }_{\text {leak }}<I_{\text {leak }}$, and $\rho(V)$ is larger than we would estimate if we could exclude the leak. This is because the $\rho(V)$ calculation involves subtracting currents in the absence of 5HT from currents in the presence of 5HT, and we may be subtracting too much. However, the leak does not affect the calculation $I_{5 \mathrm{HT}}=I / \rho$, because total current divides out in this ratio. This does not hold for $v=q / \rho$; thus, for this estimate, we must eliminate the leak. Although $I_{\text {leak }}$ is only $10 \%$ of the $5 \mathrm{HT}$ induced current at $-140 \mathrm{mV}$, it may be substantially greater at more positive potentials and could affect our estimate of $v$. For this reason, we performed fluctuation experiments near the leak reversal potential, where the current from this pathway should be minimal. The value of $\rho$ at $-20 \mathrm{mV}$ therefore is an approximation of the 5HT-induced ratio of current to flux in the absence of leak. At $-20 \mathrm{mV}, \rho=17$, which greatly exceeds one net charge per transport cycle, assuming a stoichiometry of $\mathrm{Na}^{+} / \mathrm{Cl}^{-} / 5 \mathrm{HT}^{+}$. Several groups have reported similar data for other transporters, in which currents exceed the predictions of coupled transport. For example, Sonders et al. (1996) found that in dopamine transporters, $\rho=3$ at $-20 \mathrm{mV}$ and $\rho=7$ at $-120 \mathrm{mV}$.

\section{The shot noise model}

At $-20 \mathrm{mV}$, we show that $5005 \mathrm{HT}$ molecules enter the cell per 5HT-induced channel opening and that each channel opening carries $10,000 e$. This estimate does not rely on the turnover rate or the number of transporters and is in approximate agreement with channels recorded from oocyte patches expressing a mammalian SERT (Lin et al., 1996). The channels they record are $0.4 \mathrm{pA}$ at $-20 \mathrm{mV}$, with an average open time of $2.5 \mathrm{msec}$, implying a charge transfer of $6200 \mathrm{e}$. Using the shot noise model and wholecell fluctuations to estimate channel size enabled us to perform flux assays on the same cell, which presently would be impossible in a cell-free patch. The theory assumes that every shot is $i(t)=$ $q \delta(t)$, in which case $\sigma^{2} / I=2 q B$. If we assume that events have an average width of $\Delta t$, then $\sigma^{2} / I \sim q / \Delta t$, and $q$ represents an average charge per event. The smallest $\Delta t$ that could contribute to fluctuations that are cut off at $1000 \mathrm{~Hz}$ is $\Delta \mathrm{t} \sim 0.1 \mathrm{msec} . \Delta t>0.1 \mathrm{msec}$ implies $q>3000 e$. This gives a lower limit to the number of 5HT molecules transferred per channel opening; for $\rho=17, v>176$.

\section{Transporter models}

Figure 8 describes two possible interpretations of these data. For simplicity, we show only the binding of 5HT; the binding of obligatory $\mathrm{Na}$ and $\mathrm{Cl}$ ions is implied. In $A$, we presume that 500 coupled transport cycles, $v$, occur for every elementary current. In this model, we envision two classes of events, the coupled transport of 5HT and co-transported ions, which is a small and perhaps even silent electrical event, and a 5HT-gated ion channel. The transporter flips back and forth between transporter mode and channel mode, and the channel mode occurs with low probability compared with coupled transport (Galli et al., 1995). In such a model, we would expect the ratio of current to transport to be given by $N i p / N \nu \epsilon$, where $N$ is the number of transporters, $\nu$ is the cycle rate, $\epsilon$ is the net charge transferred per cycle, $i$ is the elementary current through the open 5HT-gated channel, and $p$ is the probability of this channel being open. Thus, for the model in $A, \rho=i p / \nu \epsilon$, emphasizing that $\rho$ is a relative value requiring an independent knowledge of $i$ and $p$ to relate $\rho$ to $\nu$. Nevertheless, one can use the measured value of $\rho$ to calculate another transporter characteristic, $v=q / \rho$, the number of transporter cycles that occur per channel opening. The model illustrated in Figure $8 B$ raises the possibility that there is only one class of elementary events and that 5HT moves through the channel with other ions in a ratio determined by $\rho$. We reconcile the conduction of hundreds of 5HTs with an apparent stoichiometry of one 5HT binding to dSERT by assuming that whereas one 5HT molecule opens the transporter, $10,000 e$ pass each opening, $\sim 5 \%$ of which are $5 \mathrm{HT}$.

The relationship we have measured between uptake and currents not only provides novel data for a particular transporter, but it suggests a new strategy-the combination of flux and noise analysis-to study other transporters. If 5HT translocates exclusively via coupled transport and the major current flows through a separate state, voltage-dependent uptake must reside in the rate constants of the transport cycle, the binding affinities of 5HT or co-transported ions, or voltage-dependent stoichiometry. On the other hand, if transport and current occur in the same state, electrochemical potentials across a pore permeable to $5 \mathrm{HT}$ cations determine voltage-dependent uptake. In this case, a charged transmitter could move against its concentration gradient only at sufficiently negative voltages. This is a departure from models that assume substrate-induced currents through a pore-like structure, but retain fixed or variable stoichiometry for coupled transport (Cammack et al., 1994; Wadiche et al., 1995; Lin et al., 1996; Sonders et al., 1997). However, it relates to a recent model proposed by $\mathrm{Su}$ et al. (1996). A 5HT channel would imply that in some cases, clearance may result from the conduction of transmitters through an open pore.

\section{REFERENCES}

Amara SG, Kuhar MJ (1993) Neurotransmitter transporters: recent progress. Annu Rev Neurosci 16:73-93.

Blakely RD, Berson HE, Fremeau Jr RT, Caron MG, Peek MM, Prince $\mathrm{KH}$, Bradley CC (1991) Cloning and expression of a functional serotonin transporter from rat brain. Nature 354:66-70.

Bruns KJ, Engert F, Lux HD (1993) A fast activating presynapse reuptake current during serotonergic transmission in identified neurons of Hirudo. Neuron 10:559-572.

Cammack JN, Schwartz EA (1993) Ions required for the electrogenic transport of GABA by horizontal cells of the catfish retina. J Physiol (Lond) 472:81-102.

Cammack JN, Schwartz EA (1996) Channel behavior in a $\gamma$-aminobutyrate transporter. Proc Natl Acad Sci USA 93:723-727.

Cammack JN, Rakhilin SV, Schwartz EA (1994) A GABA transporter operates asymmetrically and with variable stoichiometry. Neuron 13:949-960.

Cool DR, Leibach FH, Ganapathy V (1990) Modulation of 5HT uptake kinetics by ions and ion gradients in human placental brush-border membrane vesicles. Biochemistry 29:1818-1822.

Corey YL, Quick MW, Davidson QN, Lester HA, Guastella J (1994) A cocaine-sensitive Drosophila serotonin transporter: cloning, expression, and electrophysiological characterization. Proc Natl Acad Sci USA 91:1188-1192.

Costa PF, Emilio MG, Fernandes PL, Gil Ferreira H, Gil Ferreira K (1989) Determination of ionic permeability coefficients of the plasma membrane of Xenopus laevis oocytes under voltage clamp. J Physiol (Lond) 413:199-211.

Dascal N (1987) The use of Xenopus oocytes for the study of ion channels CRC. Crit Rev Biochem 22:317-387.

DeFelice LJ (1981) Introduction to membrane noise. New York: Plenum.

DeFelice LJ, Blakely RD (1996) Pore models for transporters? Biophys J 70:579-580.

Demchyshyn LL, Pristupa ZB, Sugamori KS, Barker EL, Blakely RB, Wolfgang WJ, Forte MA, Niznik HB (1994) Cloning, expression, and localization of a chloride-facilitated, cocaine-sensitive serotonin transporter from Drosophila melanogaster. Proc Natl Acad Sci USA 91:5158-5162. 
Galli A, DeFelice LJ, Duke BJ, Moore KR, Blakely R (1995) Sodium dependent norepinephrine-induced currents in norepinephrinetransporter-transfected HEK-293 cells blocked by cocaine and antidepressants. J Exp Biol 198:2197-2212.

Galli A, Blakely R, DeFelice LJ (1996) Norepinephrine transporters have channel modes of conduction. Proc Natl Acad Sci USA 93:8671-8676.

Kanner BI, Bendahan A (1985) Transport of 5HT in membrane vesicles from rat basophilic leukemia cells. Biochim Biophys Acta 816:403-410.

Larson HP, Picaud SA, Werblin FS, Lecar H (1996) Noise analysis of the glutamate-activated current in photoreceptors. Biophys J 70:733-742.

Lester HA, Mager S, Quick MW, Corey JL (1994) Permeation properties of neurotransmitter transporters. Annu Rev Pharmacol Toxicol 342:219-249.

Lin F, Lester HA, Mager S (1996) Single-channel currents produced by the serotonin transporter, and analysis of a mutation affecting ion permeation. Biophys J 71:3126-3135.

Mager S, Churl M, Henry DJ, Chavkin C, Hoffman BJ, Davidson N, Lester HA (1994) Conducting states of a mammalian serotonin transporter. Neuron 12:845-859.

Nelson PJ, Rudnick G (1979) Coupling between platelet 5-HT and K transport. J Biol Chem 254:10084-10089.

Quick MW, Naeve J, Davidson N, Lester HA (1992) Incubation with horse serum increases viability and decreases background neurotransmitter uptake in Xenopus oocytes. Biotechniques 13:357-361.

Ramamoorthy S, Bauman AL, Moore KR, Han H, Yang-Feng T, Chang AS, Ganapathy V, Blakely R (1993) Antidepressant and cocaine- sensitive human serotonin transporter: molecular cloning, expression, and chromosomal localization. Proc Natl Acad Sci USA 90:2542-2546.

Reith ME, Zimanyi I, O'Reilly (1989) Role of ions and membrane potential in uptake of serotonin into plasma membrane vesicles from mouse brain. Biochem Pharmacol 38:2091-2097.

Rudnick G (1996) Mechanisms of biogenic amine neurotransmitter transporters. In: Neurotransmitter transporters: structure, function, and regulation (Maarten EA Reith, ed), pp 73-100. Totowa, NJ: Humana.

Rudnick G, Clark J (1993) From synapse to vesicle: the reuptake and storage of biogenic amine neurotransmitters. Biochim Biophys Acta 1144:249-263.

Rudnick G, Nelson PJ (1978) Platelet 5-hydroxytryptamine transport. J Biol Chem 254:4631-4635.

Sonders M, Amara SG (1996) Channels in transporters. Curr Opin Neurobiol 6:294-302.

Sonders M, Zhu S-J, Zahniser N, Kavanaugh MP, Amara S (1997) Multiple ionic conductances of the human dopamine transporter: the actions of dopamine and psychostimulants. J Neurosci 17:960-974.

Su A, Mager S, Mayo SL, Lester H (1996) A multi-substrate single file model for ion-coupled transporters. Biophys J 70:762-777.

Vandenberg RJ, Arriza JL, Amara SG, Kavanaugh MP (1995) Constitutive ion fluxes and substrate binding domains of human glutamate transporters. J Biol Chem 270:17668-17671.

Wadiche JI, Amara SG, Kavanaugh MP (1995a) Ion fluxes associated with excitatory amino acid transport. Neuron 15:721-728.

Wadiche JI, Arriza JL, Amara SG, Kavanaugh MP (1995b) Kinetics of a human glutamate transporter. Neuron 14:1019-1027. 